\title{
Correction to: Discovering proteomics in pediatric brain tumors
}

\section{Gianpiero Tamburrini $^{1} \cdot$ Claudia Desiderio $^{2}$}

Published online: 15 December 2020

(C) Springer-Verlag GmbH Germany, part of Springer Nature 2020

\section{Correction to: Child's Nervous System https://doi.org/10.1007/s00381-020-04957-0}

Unfortunately in the original publication, the name and affiliation provided for the author Claudia Desiderio was incorrect. The correct name and the only affiliation for this Author should read as follows: Claudia Desiderio, Institute of Science and Chemical Technologies "Giulio Natta", National Research Council, Rome, Italy.

The original article has been corrected.

Publisher's note Springer Nature remains neutral with regard to jurisdictional claims in published maps and institutional affiliations.

The online version of the original article can be found at https://doi.org/ $10.1007 / \mathrm{s} 00381-020-04957-0$

\footnotetext{
Gianpiero Tamburrini gianpiero.tamburrini@unicatt.it

1 Pediatric Neurosurgery, Institute of Neurosurgery, Fondazione Policlinico Gemelli, IRCCS, Università Cattolica del Sacro Cuore, Largo “A. Gemelli”, 8, 00168 Rome, Italy

2 Institute of Science and Chemical Technologies "Giulio Natta", National Research Council, Rome, Italy
} 